\title{
Aspects Affecting the Use of Digital Technologies in Greek Schools
}

\author{
Sotiria Foutsitzi ${ }^{1} \&$ George Caridakis ${ }^{1}$ \\ ${ }^{1}$ Cultural Technology Department, University of the Aegean, Lesvos, Greece \\ Correspondence: Sotiria Foutsitzi, Cultural Technology Department, University of the Aegean, University Hill, \\ Mytilene 81100 Lesvos, Greece. E-mail: sofout@aegean.gr, gcari@aegean.gr
}

Received: June 19, 2020

doi:10.5539/ies.v14n5p145
Accepted: August 15, $2020 \quad$ Online Published: April 28, 2021

URL: https://doi.org/10.5539/ies.v14n5p145

\begin{abstract}
This paper is analyzing feedback collected from Greek high school teachers, in order to answer questions regarding the use of Information and Communication Technologies (ICT) as part of their teaching practices in Greek schools. Various hypothesis tests are presented, in order to focus on perceptions, look into possible problems and see how teachers of different profile and specializations apply ICT in their teaching. A special focus is placed on philogists, as the most populous but also less technology-related subject, content-wise. In particular, an online survey was prepared, aiming at collecting information regarding the use of ICT in Greek schools. This information is analyzed across various demographic and profession-related variables concerning teacher's age, gender, specialization, type of technology used, familiarization with ICT, motivations. A total of 309 respondents reacted to the questionnaire, over a period of about two months in 2019. The questionnaire consisted of 31 questions in total. The analysis that follows is both descriptive and statistical, while it intends to provide answers and correlations regarding the most striking questions and hypotheses.
\end{abstract}

Keywords: ICT in education, teacher demographics and ICT, motivation behind using ICT, hypotheses testing within ICT in learning, Greek schools and ICT

\section{Introduction}

\subsection{The Problem}

Nowadays, technology is mature enough for a versatile use in learning and its role in education needs to be seen from various points of view: central policies, technical infrastructures, personnel and student IT skills, trust in technology, the influence of social factors and the nature of the courses, all constitute dimensions that must be examined when designing learning tools using ICT. As the work reported in (Tassi, 2014) highlights, training on ICT is not merely a matter of technical training for teachers, as this would only create teachers adopting digital, teacher-centric strategies. Instead, the use of ICT along with proper pedagogical strategies must be in the focus of training, building on a more student-centric adoption of ICT in schools, supporting critical thinking and active learning and participation (González-González \& Jiménez-Zarco, 2015; Lee et al., 2016). Such conclusions have been reached also in Knowlton (2000) and Hannafin et al. (1997).

Moreover, although ICT is now part of, not only the education field but, practically, a wide gamut of societal aspects, it remains to be seen in what way is ICT employed by teachers, what are the qualitative characteristics of ICT usage and how far do teachers go in using it, what are those demographical (and beyond) factors that affect the uptake of ICT solutions in class? These are the questions that the current research is trying to approach from multiple points of view, focusing on the case of a South European country, namely, Greece. Greece has just recovered from a long financial crisis which caused the deprivation of significant resources in many areas of the public but also private fields. Education, being mostly public in Greece, has also been forced to adjust and, as a consequence, new technologies in schools have been introduced to a lesser extent than needed. However, Greek teachers, to a great extent, appear to be making extensive use of ICT in their profession, driven also by personal motivation, but also from policies and online resources, many of which being also supported by central authorities. The goal of this work is, thus, to examine the field, to answer the questions above related to the Greek educational scenery, parallelize the findings with the international literature and assist in taking the right measures and/or in focusing on those areas that would benefit the most from the right policy measures.

\subsection{Importance of the Problem}

This work is based on the assumption that not everyone perceives ICT in the same way. There is an abundance of 
ICT tools nowadays, ranging from simple video projectors up to augmented reality devices. Technologies such as serious games, online quizzes and collaborative environments, dedicated social media, even robotics, have found their place in the field of education and their pedagogical value has been grounded by a lot of works (Foutsitzi \& Caridakis, 2019). At the same time, different courses may require different uses of technology, while the role of factors such as age, gender, and teacher discipline, is important to look into. Moreover, the support or, at least, the way education professionals perceive the support offered by central governments, plays a significant role, while the exposure of teachers to training is important in making use of ICT in class. Finally, the reasons why ICT may (or may not) be important in the educational duties of a teacher and related stereotypes are examined. In this work, a large scale survey was conducted and was administered to a sample of 309 education professionals in the Greek secondary level (Gymnasium, Lyceum) education system. The outcomes of this research are analytically presented and discussed, making use of hypothesis tests in order to derive statistically significant findings.

\subsection{Related Work}

Technology nowadays is in a very good position to place the student in the centre of learning: online repositories and MOOCs (Massive Open Online Courses) (Pappano, 2012), interactive whiteboards (Mercer et al., 2010), robots (Jones \& Castellano, 2018), the use of Artificial Intelligence for personalized learning (Athanasiadis et al., 2019), serious games (Athanasiadis et al., 2017), but also cross-cultural digital platforms encouraging collaborations among groups of students, schools, even countries (Scimeca et al., 2009) open new horizons in education.

While teachers and schools are positive in making use of ICT in teachng, we conclude that there is still a lot of room for improving one's own pedagogical strategies. Improvement can come from various directions. These can be both internal, relating to mere skills, and external, relating to central policies, curricula and school programmes (Bingimlas, 2009), (Al-Alwani, 2005). In one of the broadest surveys on the use of ICT in education, on a European level (Wastiau et al., 2013), the positive stance of teachers and school Chairs regarding the use of ICT in learning has been highlighted. In that work, however, emphasis was given, not only on technical aspects involving latest technologies in the educational procedure (e.g. infrastructure or technical training for teachers) but, also, on how policies (Law et al., 2006) can improve towards this direction. Indeed, learning, nowadays, should adopt probably a less formal and rigid character, given the wide availability of information, as well as the exposure of students to it, not only in the school, but also during other activities. In this respect, the role of mobile smart devices and other modern media, should also be significantly considered.

The factors explained above are also complemented by other dimensions, maybe of a more complicated nature. A deeper and more substantial adoption of ICT in education may require both a change in mentality for many teachers, but also a series of changes in central policies. A number of surveys have highlighted the role of individual differences (Gil-Flores et al., 2017) while one of the most dominant and ubiquitous aspects in the uptake of ICT remains the teacher's discipline. Science, Technology, Engineering and Mathematics (STEM) teachers have higher degrees of self-confidence and familiarity in using ICT in their profession, while, other disciplines (e.g. social sciences) may have a more neutral or even negative attitude towards making use of ICT in teaching (Tassi et al., 2014). Another aspect that has been researched is that of teacher's age, where the fundamental hypothesis is that the older a teacher, the less familiar they will be with modern, state-of-the-art tools. The role of the gender of the teacher also seems to still be playing a role, at least in some countries. This becomes even more evident if one considers that the area of STEM is still man-governed, despite the amount of efforts and policies imposed by many governments to change this scene by encouraging the participation of females in STEM-related areas within and beyond education. Such a correlation between STEM being man-governed and uptake of ICT mostly by male teachers has been the topic of research in many works (Serin et al., 2015). However, it should be noted that such results vary significantly among different countries, whereas, in many other works, teacher gender does not appear to be statistically involved once other features are identified as important (Gil-Flores et al., 2017).

\section{Method}

\subsection{Study Design}

Our online questionnaire dealt with questions based on the use of ICT in teaching in Greek schools. It consisted of 31 questions, all answered by teachers $(\mathrm{N}=309)$ teaching in Greek schools, and focused on analyzing percepts and facts relating to the adoption of ICT in schools. One of the focal points is to compare its penetration in philological courses that, traditionally, have followed less digital means, as well as to examine the role of the age and gender of the teacher in the integration of ICT in class. The answers to the questions had variable response formats depending on the question (yes/no, Likert-type anchored 1-3, Likert-type anchored 1-5, closed-ended questions, open-ended questions and multiple response questions). The first questions consisted of teacher profile-related 
questions including gender, age, and specialization, while the main geographical location where the teacher worked for the past 5 years prior to the survey was asked, as well. The rest of the questions related to the reasons behind using ICT in teaching, technologies used, opinions about advanced technologies (e.g. robots and serious games), stance regarding stereotypes about the use of ICT across genders, prior training of the teacher, as well as how the teacher sees the role of the state.

\subsection{Participant Characteristics}

The link to the online survey was disseminated in various mailing lists and social media and was open for answers for a period of about 3 months in 2019. Most of the respondents were women $(\mathrm{N}=228,73.8 \%)$ while $\mathrm{N}=81(26.2 \%)$ were men. In terms of age, the majority of the sample was $41-50$ years old $(\mathrm{N}=135,43.7 \%), 27.2 \%(\mathrm{~N}=84)$ was 31-40 years old, while $17.2 \%(\mathrm{~N}=53)$ was 51-60 years old. More than one out of three educators were Philologists $(\mathrm{N}=109,35.3 \%)$. The participants taught in one school or more, of different education levels. 147 of the teachers taught in Higher secondary education (general high school, lyceum), 139 of the sample taught in Lower secondary education (junior high school, gymnasium), 58 in Primary education and another 27 of the teachers that replied work for other institutions. Teachers who taught at the level of gymnasium mostly worked in a general gymnasium $(\mathrm{N}=116$ out of $139,83.4 \%)$, whereas, among teachers who taught at the level lyceum, $68.0 \%(\mathrm{~N}=100)$ taught in general lyceum and $21.7 \%(\mathrm{~N}=32)$ taught in vocational schools (EPAL). Last but not least, $22.0 \%(\mathrm{~N}=68)$ of the participants worked in schools in Athens, $12.0 \%(\mathrm{~N}=37)$ in Thessaloniki, $15.2 \%(\mathrm{~N}=47)$ in a prefecture's capital, while the rest $43.7 \%(\mathrm{~N}=135)$ around different areas of Greece. Moreover, a 7.1\% of our respondents are coming from secondments abroad, in Greek schools in Europe and beyond.

\subsection{Instruments Used}

Demographic variables are expressed as absolute $(\mathrm{N})$ and relative frequency (\%) in each category of the variable. All datasets were tested for normality using the Kolmogorov- Smirnov normality test (when the sample size was $\mathrm{N}>30$ ) and Shapiro-Wilk test (when the sample size was $\mathrm{N}<30$ ). The results of this test should not be statistically significant so as to meet the assumption of normality. A Pearson chi-square test was performed to assess possible differences that may exist in two categorical variables. Fisher's Exact test was used when the assumption of Pearson chi-square test was violated. Depending on the distribution of a continuous variable in each cohort, either the t-test or the Mann-Whitney test was used to assess for differences. All statistic tests were two-tailed, with significance set at $\mathrm{p}<.05$. All statistical analyses were performed with SPSS 22.0 for Windows (SPSS; Chicago, IL, USA).

\section{Results}

\subsection{Descriptive Statistics in ICT Use}

Initially, respondents were asked if they use ICT in their teaching, on a five-point Likert scale. The majority rated from 3 to 5 points (1: Not at all, 5: Very much), while the mean of the rating is 3.69 points. Over $84 \%$ of the participants reported average ( 3 out of 5 ) to high ( 5 out of 5) use of technology in their profession, showing the extent to which ICT has entered today, and the teaching procedure in formal education. Figure 1 presents teachers' main reasons for using ICT in their classrooms and was only answered by those who consider themselves as making active of ICT. Note that percentages in brackets are calculated based on the respondents who reacted to this question (i.e. those who consider themselves as making active use of ICT in class). 


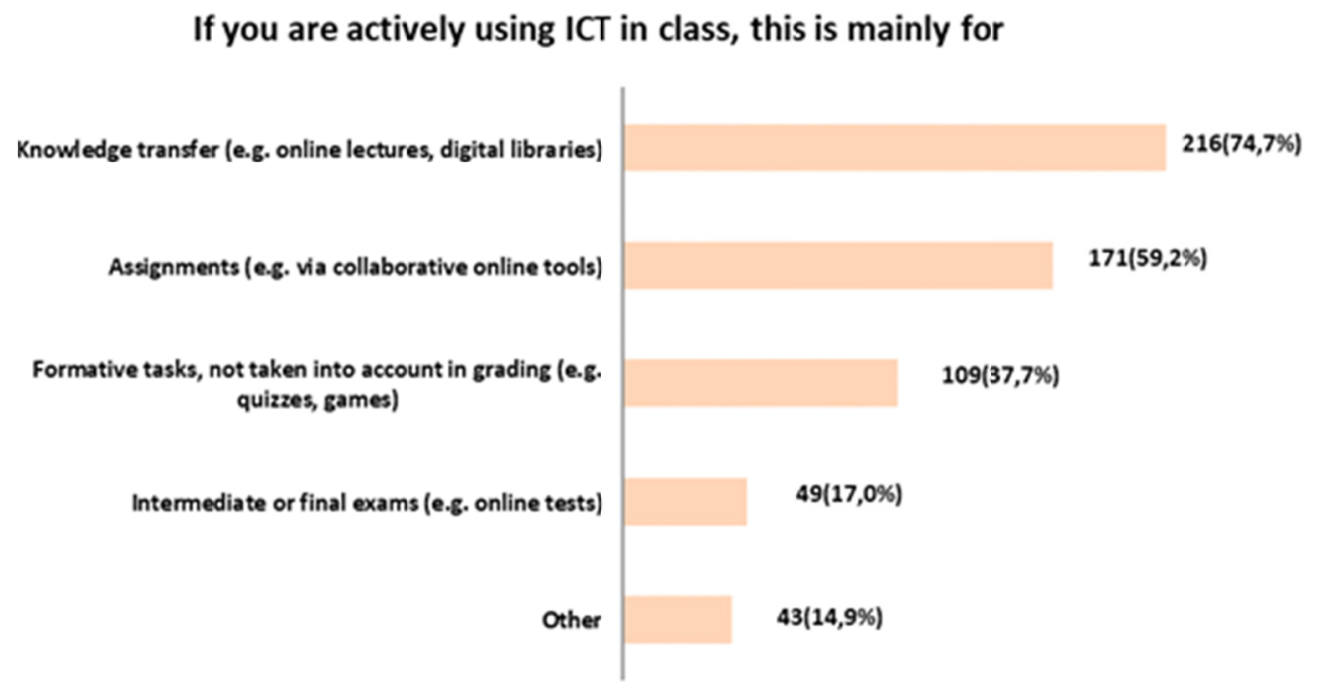

Figure 1. Frequency of the question "If you are actively using ICT in class, this is mainly for:"

Figure 2 presents the reasons why some teachers would not make extensive or full use of ICT, ordered by reported frequency. That is, these teachers may or may not be using ICT actively, but, in any case, they would like to have the option to make a more extensive use of the available tools in their profession. The main reason given by those teachers, is that they are not provided with sufficient equipment $(\mathrm{N}=51,39.8 \%)$. Note that percentages are based on only those teachers that answered this question.

\section{If you do not make use of ICT, or you simply use it to a small extent (e.g. note taking and making lists of names), what would you say are the main reasons for this?}

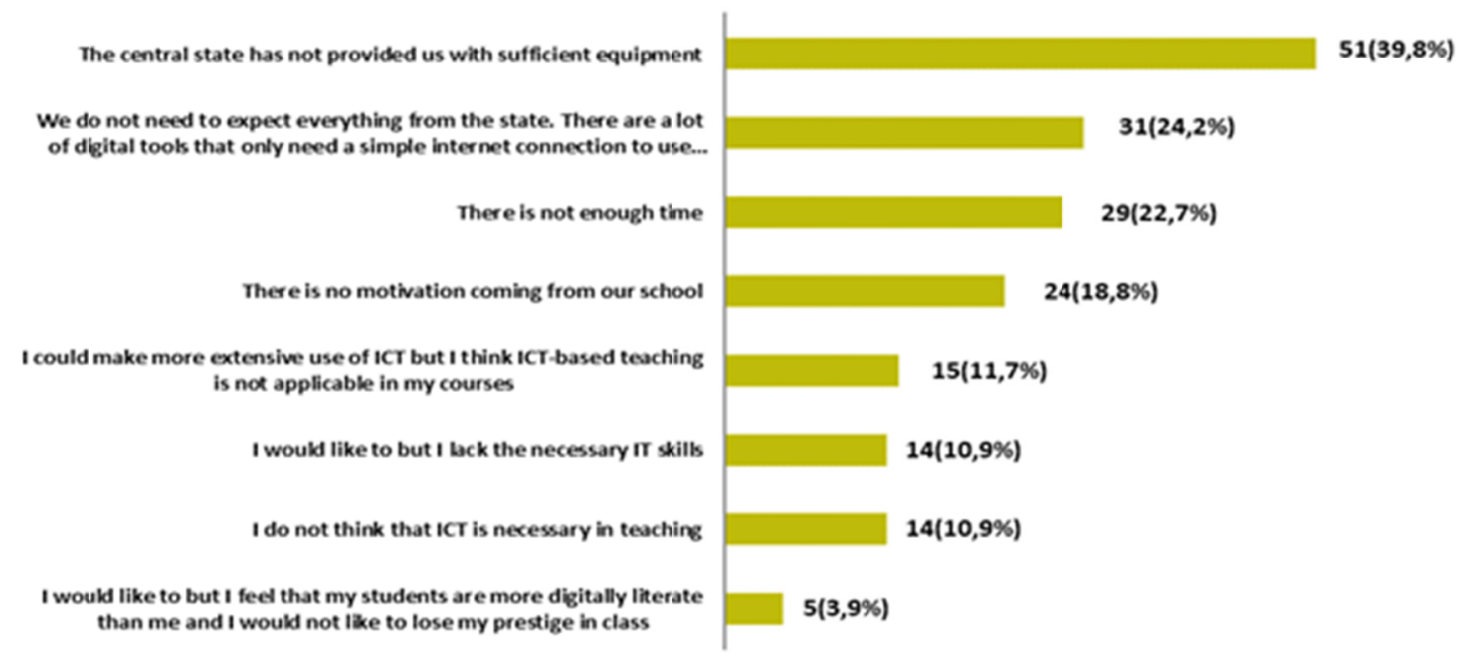

Figure 2. Frequency of the responses to the question: "If you do not make use of ICT, or you simply use it to a small extent (e.g. note taking and making lists of names), what would you say are the main reasons for this?"

The following two questions concern the use of state-of-the-art technologies in ICT. Namely, serious games and social robotics (Jones \& Castellano, 2018). The results concerning the acceptance of these technologies are very high in both cases. A very large percentage of participants believe that using serious games as a teaching method can be extremely effective ( $\mathrm{N}=247,80 \%)$, while only $4 \%$ of them $(\mathrm{N}=13)$ are negative. Regarding the usage of a 
robot in the classroom, although the teachers appear a little more negative, they still overall appear to have a positive stance. About half of the respondents $(\mathrm{N}=151,49 \%)$ seemed to believe that the use of a robot assistant in their classroom could assist students given that it is technically and functionally reliable.

Almost all of the teachers $(\mathrm{N}=293,94.82 \%)$ reported they are willing to invest personal time to develop educational material supported by ICT, whereas $5.18 \%(\mathrm{~N}=16)$ would not. Finally, according to the responses, the majority of the teachers $79.61 \%(\mathrm{~N}=246)$ has received training regarding the use of ICT in teaching, while a $20.39 \%(\mathrm{~N}=63)$ has not.

Participants were asked if they were satisfied with the support the state offers in terms of ICT in education. Their answers were given on a five-point Likert scale (1: not at all, 5: very much). The majority believes that there is limited support from the state (mean=2.26). In particular, a $60.5 \%$ of the respondents answered that the support they get from central state regarding equipment or any other needed resources, is from limited ( 2 out of 5), up to very limited (1 out of 5).

As to the question "Do you think that the use of ICT is also a matter of the teacher's gender?" participants stated $(\mathrm{N}=262,86 \%)$ that gender plays no role whatsoever in the use of ICT, an $8 \%$ answered that they do not know, while a $6 \%$ said that the gender does play a role in making use of ICT in educational procedures. More in-depth results regarding the role of teacher's gender in the use of ICT follows in subsection 3.2.1.

\subsection{Hypotheses Testing}

The remainder of this section deals with analysing the impact of different variables on different aspects related to the use of ICT for teaching. In particular, we analyse hypotheses regarding the impact of the gender, the age, and the discipline, focusing on comparing philological courses with the rest of the disciplines. Where statistical differences are found, these are based and commented on, on the ground of relative values (percentages), instead of absolute values (sample sizes).

\subsubsection{The Impact of Gender on the Use of ICT}

The nonparametric Mann-Whitney U test was used to investigate statistically significant differences between genders on the related, five-point Likert scale question "Do you use ICT in your teaching?". It was noticed that there were no statistically significant differences in the mean score of ICT use between men and women $(p$-value $=0.386)$. This suggests that both female and male teachers, in our questionnaire, are reporting an overall equal amount of use of ICT in their teaching. A chi-square test indicated that there is no statistically significant difference between genders in relation to the question why participants use ICT in their teaching ( $\mathrm{p}$-value $=0.348$ ). The only noticeable exception is the answer which attributes the use of ICT to the creation and maintenance of student lists (about $35 \%$ of men vs $21 \%$ of women chose this option).

There is a statistically significant difference between the two genders in the frequency for the reasons for which participants do not make use ICT, or simply use it to a small extent (p-value $<0.05$, Table 1 ). Specifically, $20 \%$ of the male respondents reported that they could make more extensive use of ICT but they believe ICT-based teaching is not applicable in their courses, whereas the relative percentage of women concurring to this is much lower $(9.2 \%)$. However, in relation to the answer "there is not enough time", the male gender responded by $13.3 \%$ whereas the female gender responded by $25.5 \%$, indicating a possibly higher concern for time availability among women. 
Table 1. Significance test related to gender on the question: If you do not make use of ICT, or you simply use it to a small extent (e.g. note taking and making lists of names), what would you say are the main reasons for this?

\begin{tabular}{|c|c|c|c|c|}
\hline & Man & Woman & \multirow{2}{*}{$\begin{array}{c}\mathrm{X}^{2} \\
\text { value }\end{array}$} & \multirow{2}{*}{ p-value } \\
\hline & $\mathrm{N}(\%)$ & $\mathrm{N}(\%)$ & & \\
\hline There is not enough time & $4(13.3 \%)$ & $25(25.5 \%)$ & \multirow{8}{*}{17.54} & \multirow{8}{*}{0.025} \\
\hline $\begin{array}{l}\text { I could make more extensive use of ICT but I think ICT-based teaching is } \\
\text { not applicable in my courses }\end{array}$ & $6(20.0 \%)$ & $9(9.2 \%)$ & & \\
\hline There is no motivation coming from our school & $5(16.7 \%)$ & $19(19.4 \%)$ & & \\
\hline I would like to but I lack the necessary IT skills & $2(6.7 \%)$ & $12(12.2 \%)$ & & \\
\hline $\begin{array}{l}\text { I would like to but I feel that my students are more digitally literate than me } \\
\text { and I would not like to lose my prestige in class }\end{array}$ & $2(6.7 \%)$ & $3(3.1 \%)$ & & \\
\hline I do not think that ICT is necessary in teaching & $8(26.7 \%)$ & $6(6.1 \%)$ & & \\
\hline The central state has not provided us with sufficient equipment & $10(33.3 \%)$ & $41(41.8 \%)$ & & \\
\hline $\begin{array}{l}\text { We do not need to expect everything from the state. There are a lot of digital } \\
\text { tools that only need a simple internet connection to use them. Students can } \\
\text { use them as part of their learning material and for their assignments. }\end{array}$ & $9(30.0 \%)$ & $22(22.4 \%)$ & & \\
\hline
\end{tabular}

As far as the question "Would you make serious games part of your teaching?" statistically significant differences were found in relation to gender ( $\mathrm{p}$-value $=0.046$ ). In particular, $89.9 \%$ of men answered that they would make serious games part of their teaching, whereas the total number of women answering positively amounted to $96.9 \%$. A Pearson chi-square test was performed to assess possible differences that may exist in the two categorical variables "Gender" and "Would you make use of a robot assistant in class, given that it is technically and functionally reliable?" A chi-square test indicated that there is no statistically significant difference between gender and the use of a robot assistant in class ( $p$-value $=0.623$ ).

Examining whether there is a difference in the answers given to the question "Would you use personal time to develop teaching material based on ICT?" between males and females, it was derived that there is no statistically significant difference ( $\mathrm{p}$-value $=0.379$ ), and respondents from both genders replied positively to their vast majority.

It was noticed that there is no statistically significant difference between genders regarding the question "Do you think that the use of ICT is also a matter of the teacher's gender" ( $p$-value $=0.579)$. Respondents from both genders report, to a great extent, that the use of ICT in teaching is not a matter of the teacher's gender, with female respondents answering no to the question being proportionally a bit higher than the male ones $(94.3 \% \mathrm{vs} 91.9 \%)$. However, this difference is not statistically significant.

Regarding the question "If you are actively using ICT in class, this is mainly for:" statistically significant differences were seen between the two genders ( -value $<0.05)$ (Table 2). These differences mainly come from men's tendency to make higher use of online repositories while women tend to employ ICT for assignments to a greater extent than their male colleagues.

Table 2. Significance test related to gender on the question: If you are actively using ICT in class, this is mainly for

\begin{tabular}{|c|c|c|c|c|}
\hline & Man & Woman & \multirow{2}{*}{$\begin{array}{c}X^{2} \\
\text { value } \\
\end{array}$} & \multirow{2}{*}{ p-value } \\
\hline & $\mathrm{N}(\%)$ & $\mathrm{N}(\%)$ & & \\
\hline $\begin{array}{l}\text { Formative tasks, not taken into account in grading (e.g. } \\
\text { quizzes, games) }\end{array}$ & $28(38.9 \%)$ & $81(37.3 \%)$ & \multirow{5}{*}{13.18} & \multirow{5}{*}{0.022} \\
\hline Intermediate or final exams (e.g. online tests) & $12(16.7 \%)$ & $37(17.1 \%)$ & & \\
\hline Knowledge transfer (e.g. online lectures, digital libraries) & $60(83.3 \%)$ & $156(71.9 \%)$ & & \\
\hline Assignments (e.g. via collaborative online tools) & $32(44.4 \%)$ & $139(64.1 \%)$ & & \\
\hline Other & $13(18.1 \%)$ & $30(13.8 \%)$ & & \\
\hline
\end{tabular}

\subsubsection{The Impact of Age on the Use of ICT}

The next focus area is the impact of age on the use of ICT. Given that, at the time of this research, computer-based learning, internet and overall ICT were already a well-integrated part of our everyday life for over two decades, it was decided to split the respondents in two groups: those younger than 50 years old and those older than this age. The main motivation behind this was that, at the time the second group ( $>50$ years old) started their teaching 
career, ICT was not very widespread in education and, thus, these professionals would undergo a (self-) adaptation procedure in order to adopt computer-based technologies in their teaching activities. On the other side, for professionals younger than 50 years old, it is more possible that ICT was already at a more mature stage in teaching activities and learning, even in a less structured or advanced stage than today (e.g. using webpages, search engines, e-learning resources (Hannafin \& Land, 1997; Keller, 1995)).

It was noticed through a nonparametric Mann-Whitney $U$ test that there were no statistically significant differences in the mean score of ICT use between " $<50$ years" and " $>50$ years" participants ( $p$-value $=0.092$ ). However, we can still notice a difference in the mean values given by the two groups, with the younger teachers reporting an overall higher rate of ICT usage (mean=3.74/5.00) and the older ones reporting a lower one $(3.50 / 5.00)$.

Considering the findings illustrated in Table 3 , the chi-square test indicates that there is no statistically significant difference between the two age groups in relation to the question why participants use ICT in their teaching $(p$-value $=0.273)$. The only significant difference between the age groups appears to be the fact that younger teachers answered that they are looking for online tools, games, and quizzes and bring them in class to a larger extent than their older colleagues ( $52.1 \%$ versus $30.0 \%$, respectively). Percentages in brackets are calculated based on the number of available answers per age group.

Table 3. Significance test related to age regarding the question 'What are the reasons of using ICT in your teaching?'

\begin{tabular}{|c|c|c|c|c|}
\hline & $\leq 50$ years & $>50$ years & \multirow{2}{*}{$\begin{array}{c}\mathrm{X}^{2} \\
\text { value }\end{array}$} & \multirow{2}{*}{ p-value } \\
\hline & $\mathrm{N}(\%)$ & $\mathrm{N}(\%)$ & & \\
\hline Support in creating and maintaining student lists & $57(23.6 \%)$ & $17(28.3 \%)$ & \multirow{10}{*}{12.18} & \multirow{10}{*}{0.273} \\
\hline Show videos to the students & $183(75.6 \%)$ & $44(73.3 \%)$ & & \\
\hline Prepare tests with the help of a computer & $160(66.1 \%)$ & $43(71.7 \%)$ & & \\
\hline Tests and notes & $159(65.7 \%)$ & $41(68.3 \%)$ & & \\
\hline Power point presentations & $166(68.6 \%)$ & $39(65.0 \%)$ & & \\
\hline Online tools that help me share material with students & $102(42.1 \%)$ & $22(36.7 \%)$ & & \\
\hline I find tools (e.g. tutorials, games, quizzes online and use them in class & $126(52.1 \%)$ & $18(30.0 \%)$ & & \\
\hline I ask from students to work on their assignments using ICT & $130(53.7 \%)$ & $33(55.0 \%)$ & & \\
\hline I make use of social networks in teaching & $49(20.2 \%)$ & $14(23.3 \%)$ & & \\
\hline Other & $18(7.4 \%)$ & $5(8.3 \%)$ & & \\
\hline
\end{tabular}

Regarding the question "Would you make serious games part of your teaching?" statistically significant differences were found in relation to age ( $\mathrm{p}$-value $=0.018$ ). Specifically, $87.5 \%$ of participants with age " $>50$ years" answered that they would make serious games part of their teaching, whereas the total number of participants with age " $\leq 50$ years" answering positively amounted to $96.7 \%$. A Pearson chi-square test was performed to assess possible differences that may exist within the two categorical variables "Age" and the hypothetical use of a robot in class. The chi-square test indicated that there is no statistically significant difference for the two age groups and their answers ( $\mathrm{p}$-value $=0.231$ ). However, a tendency of the younger group to answer more positively has to be noted $(74.4 \%$ vs $65.0 \%)$.

Examining whether there is a difference in the answers given to the question "Would you use personal time to develop teaching material based on ICT?" between participants with age " $\leq 50$ years" and " $>50$ years", there is no statistically significant difference between the two age groups ( $p$-value $=0.746$ ). The participants, in both age groups, showed a strong willingness to invest personal time in developing electronic teaching material.

The nonparametric Mann-Whitney $U$ test was used to investigate statistically significant differences between the two age groups, on five-point Likert scale answers to the question "Are you satisfied with the support the state offers in terms of ICT to education?" It was shown that there were no statistically significant differences in the mean scores ( $p$-value $=0.573$ ), with both groups rating the support from the state below average ( 2.22 and 2.27 for the younger and the older group, respectively).

\subsubsection{The Impact of the Teacher's Discipline on the Use of ICT}

In this sub-section, the relationship between the teacher's specialization and the way they are making use of ICT in teaching is explored. The focus is placed on philologists, as the most populous but, still, one of the disciplines that seems to be benefiting the least from digital technologies. For this, reason, two types of comparisons take place for 
each test. In particular:

1) Philologists vs Science teachers (mathematics, physics-chemistry, computer science, biologists, geologists)

2) Philologists vs the Other disciplines (sociologists, psychologists, physical education teachers, art/music teachers, religious studies teachers and foreign language teachers).

It should be noted that performing comparisons between philologists and isolated disciplines alone would lead to non-reliable results, given the fact that, for many disciplines, the amount of answers received was too low for a reliable statistical analysis. For this reason, it was decided to group disciplines in these three groups, in all of which the participation of respondents was high enough to lead to reliable statistical results.

The nonparametric Mann-Whitney U test was used so as to investigate statistically significant differences between specializations regarding the general question "Do you use ICT in your teaching?". It was noticed from the results that there are indeed statistically significant differences in the mean score of ICT use between Philologists and Science teachers ( $\mathrm{p}$-value $=<0.001$ ). More specifically, Science teachers had a greater mean score than Philologists (Mean: 4.09 vs 3.45 and Mean Rank: 102.21 vs 73.13). In addition, there were statistically significant differences in the mean score between Philologists and "Other disciplines" (p-value=0.030). More specifically, "Other disciplines" had greater mean score than "Philologists" (Mean: 3.72 vs 3.45 and Mean Rank: 135.39 vs 115.91). These outcomes highlight that philologists are indeed among the groups of disciplines where the least use of ICT is made.

A Pearson chi-square test was performed to assess possible differences that may exist in the two categorical variables "Specialization" (Philologists vs Science teachers) and "What are the reasons of using ICT in your teaching" (multiple response variables). Considering the findings illustrated in Table 4, the chi-square test indicates that there is statistically significant difference between Philologists and Science teachers in relation to the question why participants use ICT in their teaching ( $p$-value $=0.013$ ). In all categories, philologists make proportionally lower use of ICT than science teachers, apart from showing videos to students and preparing tests with the help of a computer.

Table 4. Significance test regarding the question 'What are the reasons of using ICT in your teaching?' for philologists and science teachers

\begin{tabular}{lll}
\hline & Philologists & Science teachers \\
& $\mathrm{N}(\%)$ & $\mathrm{N}(\%)$ \\
\hline Support in creating and maintaining student lists & $26(24.5 \%)$ & $22(39.3 \%)$ \\
\hline Show videos to the students & $80(75.5 \%)$ & $38(67.9 \%)$ \\
\hline Prepare tests with the help of a computer & $81(76.4 \%)$ & $41(73.2 \%)$ \\
\hline Tests and notes & $79(74.5 \%)$ & $45(80.4 \%)$ \\
\hline Power point presentations & $74(69.8 \%)$ & $40(71.4 \%)$ \\
\hline Online tools that help me share material with students & $37(34.9 \%)$ & $26(46.4 \%)$ \\
\hline I find tools (e.g. tutorials, games, quizzes online and use them in & $41(38.7 \%)$ & $27(48.2 \%)$ \\
class & $64(60.4 \%)$ & $35(62.5 \%)$ \\
\hline I ask from students to work on their assignments using ICT & $19(17.9 \%)$ & $13(23.2 \%)$ \\
\hline I make use of social networks in teaching & $1(0.9 \%)$ & $8(14.3 \%)$ \\
\hline Other & 0.013 \\
\hline
\end{tabular}

A Pearson chi-square test was performed to assess possible differences that may exist for the two categorical variables "Specialization" (Philologists vs Other disciplines) and "What are the reasons of using ICT in your teaching" (Multiple response variables). Considering the findings illustrated in Table 5, the chi-square test indicates that there is statistically significant difference between Philologists and Other disciplines in relation to the question ( $\mathrm{p}$-value $=<0.001$ ). Although, as noted before, the overall use of ICT between the two groups is higher for 'other disciplines', it can be seen that, for certain categories, philologists make proportionally higher usage of ICT. This is mainly seen in the preparation of tests with the help of a computer, tests and notes, as well as assignments made by the students with the help of a computer. 
Table 5. Significance test regarding the question 'What are the reasons of using ICT in your teaching?' for philologists and other disciplines

\begin{tabular}{|c|c|c|c|c|}
\hline & Philologists & Other disciplines & \multirow{2}{*}{$\mathrm{X}^{2}$ value } & \multirow{2}{*}{ p-value } \\
\hline & $\mathrm{N}(\%)$ & $\mathrm{N}(\%)$ & & \\
\hline Support in creating and maintaining student lists & $26(24.5 \%)$ & $26(18.6 \%)$ & \multirow{10}{*}{44.23} & \multirow{10}{*}{$<0.001$} \\
\hline Show videos to the students & $80(75.5 \%)$ & $109(77.9 \%)$ & & \\
\hline Prepare tests with the help of a computer & $81(76.4 \%)$ & $81(57.9 \%)$ & & \\
\hline Tests and notes & $79(74.5 \%)$ & $76(54.3 \%)$ & & \\
\hline Power point presentations & $74(69.8 \%)$ & $91(65.0 \%)$ & & \\
\hline Online tools that help me share material with students & $37(34.9 \%)$ & $61(43.6 \%)$ & & \\
\hline I find tools (e.g. tutorials, games, quizzes online and use them in class & $41(38.7 \%)$ & $76(54.3 \%)$ & & \\
\hline I ask from students to work on their assignments using ICT & $64(60.4 \%)$ & $64(45.7 \%)$ & & \\
\hline I make use of social networks in teaching & $19(17.9 \%)$ & $31(22.1 \%)$ & & \\
\hline Other & $1(0.9 \%)$ & $14(10.0 \%)$ & & \\
\hline
\end{tabular}

A chi-square test indicated that there is no statistically significant difference between specialization (Philologists vs Science teachers) and the idea of using serious games in class ( $\mathrm{p}$-value $=0.064)$, although the Philologists score higher in this. In addition, there is no statistically significant difference between the specialization of Philologists vs Other disciplines and the idea of using serious games in class, where the corresponding figures are exactly the same for both categories $(96.7 \%$, p-value $>0.999)$.

A chi-square test indicated that there is statistically significant difference between specialization (Philologists vs Science teachers) and the idea of using a robot assistant in class (p-value $=0.029) .78 .3 \%$ of the science teachers would make use of a robot assistant in class, whereas only 58.5\% of philologists would. Moreover, it was also deducted that there is statistically significant difference between specialization for Philologists and Other disciplines regarding the idea of using a robot assistant in class ( $\mathrm{p}$-value $=0.004)$. It was noticed that $79.4 \%$ of the staff members from other disciplines would make use of a robot assistant in class.

It was also shown that that there is no statistically significant difference between the specializations of Philologists and Science teachers and the thought of prejudice against the applicability of ICT on philological courses ( $p$-value=0.627). Likewise, specialization Philologists vs the category 'Other disciplines' and the thought of prejudice against the applicability of ICT in philological courses showed no statistically significant difference (p-value $=0.451$ ).

According to the tests, there is a statistically significant difference between Philologists vs Science teachers regarding whether they have received any prior training on the use of ICT in teaching ( $\mathrm{p}$-value $=0.036$ ). $83.9 \%$ of Science teachers had followed training regarding the use of ICT in teaching, whereas only $68.8 \%$ of philologists had followed related training. Moreover, a significant difference was observed also between Philologists and Other disciplines, with other disciplines amounting to $86.1 \%$ ( $\mathrm{p}$-value $=0.001$ ).

As for the findings illustrated in Table 6, the chi-square test indicates that there is no statistically significant difference between Philologists and Science teachers in relation to the question "If you are actively using ICT in class, this is mainly for..." ( $\mathrm{p}$-value $=0.099)$. However, it should be noted that, in all options, Science teachers have provided positive answers to a greater extent.

Table 6. Significance test regarding the question 'If you are actively using ICT in class, this is mainly for:' for philologists and science teachers

\begin{tabular}{|c|c|c|c|c|}
\hline & Philologists & Science teachers & \multirow{2}{*}{$\begin{array}{c}\mathrm{X}^{2} \\
\text { value }\end{array}$} & \multirow{2}{*}{ p-value } \\
\hline & $\mathrm{N}(\%)$ & $\mathrm{N}(\%)$ & & \\
\hline Formative tasks, not taken into account in grading (e.g. quizzes, games) & $37(36.6 \%)$ & $23(46 \%)$ & \multirow{5}{*}{9.276} & \multirow{5}{*}{0.099} \\
\hline Intermediate or final exams (e.g. online tests) & $13(12.9 \%)$ & $14(28 \%)$ & & \\
\hline Knowledge transfer (e.g. online lectures, digital libraries) & $72(71.3 \%)$ & $41(82 \%)$ & & \\
\hline Assignments (e.g. via collaborative online tools) & $66(65.3 \%)$ & $33(66 \%)$ & & \\
\hline Other & $11(10.9 \%)$ & $8(16 \%)$ & & \\
\hline
\end{tabular}

Table 7 shows that there is no statistically significant difference between philologists and the remaining staff in 
relation to the question "If you are actively using ICT in class, this is mainly for" ( $p$-value $=0.226)$. However, a main difference one can notice is that the philologists taking part in our questionnaire tended to choose the option related to creating assignments using online tools to a greater extent with regards to the rest of the disciplines (65.3\% and $52.2 \%$, respectively).

Table 7. Significance test regarding the question 'If you are actively using ICT in class, this is mainly for' for philologists and teaching staff from other disciplines

\begin{tabular}{|c|c|c|c|c|}
\hline & Philologists & Other disciplines & $\mathrm{X}^{2}$ & 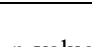 \\
\hline & $\mathrm{N}(\%)$ & $\mathrm{N}(\%)$ & value & $\mathrm{p}$-value \\
\hline $\begin{array}{l}\text { Formative tasks, not taken into account in grading (e.g. } \\
\text { quizzes, games) }\end{array}$ & $37(36.6 \%)$ & $49(35.5 \%)$ & \multirow{5}{*}{6.92} & \multirow{5}{*}{0.226} \\
\hline Intermediate or final exams (e.g. online tests) & $13(12.9 \%)$ & $22(15.9 \%)$ & & \\
\hline $\begin{array}{l}\text { Knowledge transfer (e.g. online lectures, digital } \\
\text { libraries) }\end{array}$ & $72(71.3 \%)$ & $103(74.6 \%)$ & & \\
\hline Assignments (e.g. via collaborative online tools) & $66(65.3 \%)$ & $72(52.2 \%)$ & & \\
\hline Other & $11(10.9 \%)$ & $24(17.4 \%)$ & & \\
\hline
\end{tabular}

\section{Discussion}

According to our findings, the overall population declares to be making extensive use of ICT in their teaching (score equal to $3.69 / 5.00$ with 1 corresponding to low and 5 corresponding to high usage). Although this is an encouraging finding, aligned with an abundance of recent and older works (Foutsitzi \& Caridakis, 2019), it appears that frequent ICT usage for some professionals may be associated with the use of common and, many times, passive means, such as word processors, videos, or digital slides shown in class. In other words, this question alone does not relate with the reasons or motivations why teachers use ICT and how they involve students but, instead, the intention behind this question was to get an overall impression of the degree to which teachers engage with ICT solutions in their job. A further limitation is that we mainly targeted teachers making use of online, electronic means, while the survey itself made use of an electronic online tool, namely, Google Forms. This may have favored the participation of more tech-savvy participants, although at no stage of the survey were particular IT skills necessary.

To further illustrate what participants meant by using ICT in their profession, one of the following questions was 'What is the reason of using ICT in your teaching?'. The replies showed that the main tendency of the teachers is to employ ICT solutions mainly for showing material to students (videos or power point presentations, $73.5 \%$ and $66.3 \%$, respectively), whereas more active participation of the students themselves is described by different, less popular options. It is, however, notable that teachers see a lot of future in latest technologies related to serious games and robotics, which constitutes technologies whose pedagogical value has been validated in different works (Spyrou et al., 2018). Especially, with regards to serious games, $80 \%$ of respondents are positive, while in the case of a robot assistant, half of the teachers replied affirmatively.

Subsequently, statistical tests were conducted to test hypotheses regarding the impact of teacher's age, gender and specialization in making use of ICT tools in teaching. One limitation may be that the participation of females in the questionnaire accounts for a $73.8 \%$ of the participants, overall, when, according to an earlier research of the Hellenic Statistical Authority (2014), the corresponding figure of female teachers is $67 \%$ in the Greek education system. This may be linked also to the higher participation of philologists (about $35 \%$ of participants in this questionnaire), when their representation in the overall secondary education is still high (2018) but lower than $35 \%$, namely, about $26 \%$ (Note 1). This may be explained by the fact that, over the course of the research, some participants shared the questionnaire in dedicated, discipline-specific social media groups, introducing some bias in the data which, unfortunately, was not possible to control.

One of the major conclusions relating to factors affecting the use of ICT in teachers' profession appeared to be that of prior training of them on possible usages of ICT in the classroom and for preparing educational material. Philologists reported significantly lower training than their colleagues from other subject areas. A deeper look at the data showed that philologists teaching in non-urban environments are those professionals who reported the lowest rates of training.

Amongst other findings was that female teachers tend to make more extensive use of ICT for preparing assignments while men take more advantage of online resources. However, general use of ICT in teaching did not 
show any significant difference between females and males. This is aligned with the conclusion in (Gebhardt et al., 2019), where data from the ICILS questionnaire were analyzed. The authors report that differences in the overall use of ICT, experience and disposition towards it, between female and male teachers, are small and/or inconsistent across different countries. Similar conclusions have been reached in (Semerci et al., 2018) on a sample of 353 teachers of high schools in Ankara, Turkey, while older research also supports this argument (Norris et al., 2003). However, the fact that we discovered qualitative differences in the use of ICT between males and females is a research area that deserves further research and could probably provide more insights than merely looking into percentages of teachers making generic use of ICT in their profession.

Regarding age-related hypotheses, results showed that teachers below 50 years old are making use, to a greater extent than their older peers, of online material, such as quizzes, mini games and various tools. Overall, however, the two age groups make use of ICT to a similar degree, with young professionals probably showing a higher overall usage, which was shown to not be statistically significant, though. Our findings, regarding a non-significant impact of the age on the use of ICT in class, are aligned with a number of studies (Semerci et al., 2018), although other works have found an impact of age on the usage and perception of ICT in teaching (Manisha, 2012; Merillo \& Domingo, 2019). In conclusion, it appears that this is a multi-dimensional topic and should be examined from various perspectives: how teachers use technology, what tools they choose (e.g. promoting active vs passive learning) and the reasons behind making use of ICT in class (e.g. keeping student lists or preparing exams on word processors versus encouraging interactivity among students with the help of rich online tools). We hope that our discussion on the reasons why teachers employ ICT in learning and the identified, qualitative differences between the two age groups, analyzed in this research, will open the path for such a multilateral research involving age as an independent variable.

Regarding the relationship between specialization and ICT, the major findings can be summarized as follows: Philologists appear to be making lower usage of ICT in their profession, in comparison with science teachers and, also, in comparison with the rest of the specializations. There are also significant differences related to the reasons different specializations use ICT. Few philologists use ICT supportively (e.g. for maintaining student lists), relatively few also for retrieving material online that they can integrate in their class. However, a large number of philologists design tests and assignments using ICT. Compared to science teachers and teachers coming from other disciplines, the use of robots may not be that promising among philologists. Overall, philologists make more limited use of material for formative tasks, exams, or of online material for knowledge transfer, than science teachers. These outcomes appear to be complementary to the results of a 2015 survey in Greek schools (Nikolopoulou \& Giallamas, 2015), where the authors focused on the barriers for the usage of ICT in Greek secondary education, on a sample of 119 teachers. One of the findings of their research was that literature teachers showed a greater concern regarding lack of support concerning ICT in comparison to colleagues from other disciplines.

Research on the issue of ICT integration as a function of subject areas is ongoing (Bensalem, 2019), but, to a large extent, it tends to be fragmented by country and educational system. Although there is a general belief that subject areas and ICT integration are related (Howard et al., 2015), more research is needed in order to understand the specificities of each course along with their accompanying needs in terms of ICT-based teaching and look at ICT usage in them also through this prism. Moreover, the fact that certain subjects can benefit from a wider availability of digital materials than other courses, is also a factor to take into account and consider in normalizing for comparison. Finally, rapid developments in technology and the availability of an increasing number of intelligent and sophisticated tools that, within a matter of months can become obsolete only to be replaced by more sophisticated ones, is also a factor that constitutes research in the area challenging (Karkazis et al., 2019).

\section{Acknowledgments}

This research has been co-financed by the European Regional Development Fund of the European Union and Greek national funds through the Operational Program Competitiveness, Entrepreneurship and Innovation, under the call RESEARCH - CREATE - INNOVATE (project code:T1EDK-02146).

We would like to thank Mrs. Lily Leontiou for her valuable help in hypothesis testing.

\section{References}

Athanasiadis, C., Amestoy, M., Hortal, E., \& Asteriadis, S. (2019). e-3 learning: a Dataset for Affect-driven Adaptation of Computer-Based Learning. IEEE MultiMedia, 27(1), 49-60, https://doi.org/10.1109/MMUL.2019.2945716

Athanasiadis, C., Hortal, E., Koutsoukos, D., Lens, C. Z., \& Asteriadis, S. (2017). Personalized, Affect and 
Performance-driven Computer-based Learning. Proceedings of the 2017 Conference on Computer Supported Education (CSEDU) (pp. 132-139). Porto, Portugal. https://doi.org/10.5220/0006331201320139

Bensalem, E. (2019). English Teachers' Perceptions of Technology Integration: Are They Different From Their Peers in Engineering and Medical Science? International Journal of English Linguistics, 9(1). https://doi.org/10.5 539/ijel.v9n1p152

Foutsitzi, S., \& Caridakis, G. (2019). ICT in education: Benefits, Challenges and New directions. Proceedings of the 10th International Conference on Information, Intelligence, Systems and Applications (IISA) (pp. 1-8), Patras, Greece. https://doi.org/10.1109/IISA.2019.8900666

Gebhardt, E., Thomson, S., Ainley, J., \& Hillman, K. (2019). Teacher Gender and ICT. In Gender Differences in Computer and Information Literacy (pp. 53-68). Springer. https://doi.org/10.1007/978-3-030-2 6203-7_5

Gil-Flores, J., Rodríguez-Santero, J., \& Torres-Gordillo J. J. (2017). Factors that explain the use of ICT in secondary-education classrooms: The role of teacher characteristics and school infrastructure. Computers in Human Behavior, 68(1), 441-449. https://doi.org/10.1016/j.chb.2016.11.057

González-González, I., \& Jiménez-Zarco, A.I. (2015). Using learning methodologies and resources in the development of critical thinking competency: An exploratory study in a virtual learning environment. Computers in Human Behavior, 51, 1359-1366. https://doi.org/10.1016/j.chb.2014.11.002

Hannafin, M. J., \& Land, S. M. (1997). The foundations and assumptions of technology-enhanced student-centered learning environments. Instructional Science, 25(3), 167-202. https://doi.org/10.1023/A:1002997414652

Hannafin, M. J., Hill, J. R., \& Land, S. M. (1997). Student-centered learning and interactive multimedia: Status, issues, and implication. Contemporary Education, 68(2), 94-99.

Haydn, T. (2013). Signature pedagogies, assumptions and assassins: ICT and motivation in the history classroom. Using New Technologies to Enhance Teaching and Learning in History (pp. 141-152). https://doi.org/10.4324/9780203075593-16

Howard, S. K., Chan, A., \& Caputi, P. (2015). More than beliefs: Subject areas and teachers' integration of laptops in secondary teaching. British Journal of Educational Technology, 46(2), 360-369. https://doi.org/10.1111/bjet.12139

Jones, A., \& Castellano, G. (2018) Adaptive Robotic Tutors that Support Self-Regulated Learning: A Longer-Term Investigation with Primary School Children. International Journal of Social Robotics, 1-4. https://doi.org/10.1007/s12369-017-0458-z

Kapp, K. M. (2012). The gamification of learning and instruction: game-based methods and strategies for training and education. John Wiley \& Sons. https://doi.org/10.1145/2207270.2211316

Karkazis, P., Leligou, H. C., Trakadas, P., Vretos, N., Asteriadis, S., Daras, P., \& Standen, P. (2019). Technologies Facilitating Smart Pedagogy. Didactics of Smart Pedagogy (pp. 433-451). Springer, Cham. https://doi.org/10.1007\%2F978-3-030-01551-0_22

Keller, J. M. (1995). Motivation in cyber learning environments. International Journal of Educational Telecommunications, 1(1), 7-30.

Knowlton, D. S. (2000). A theoretical framework for the online classroom: A defense and delineation of a student-centered pedagogy. New Directions for Teaching and Learning, 2000(84), 5-14. https://doi.org/10.1002/tl.841

Law, N., Pelgrum, W. J., \& Plomp, T. (2008). Pedagogy and ICT use in schools around the world: Findings from the IEA SITES 2006 Study. Springer Science \& Business Media. https://doi.org/10.1007/978-1-4020-8928-2

Lee, H., Parsons, D., Kwon, G., Kim, J., Petrova, K., Jeong, E., \& Ryu, H. (2016). Cooperation begins: Encouraging critical thinking skills through cooperative reciprocity using a mobile learning game. Computers \& Education, 97, 97-115. https://doi.org/10.1016/j.compedu.2016.03.006

Manisha, M. V. (2012). A study on secondary school teachers' attitude towards using new technologies in education. Indian Stream Research Journal, 2(8).

Mercer, N., Hennessy, S., \& Warwick, P. (2010). Using interactive whiteboards to orchestrate classroom dialogue. Technology, Pedagogy and Education, 19(2), 195-209. https://doi.org/10.1080/1475939X.2010.491230

Merillo, J., \& Domingo, P. (2019). Technology in Pedagogy: Teachers' Perception Towards the Effectiveness of 
ICT Integration in Language Teaching. SSRN Electronic Journal. http://dx.doi.org/10.2139/ssrn.3442432

Michael, D. R., \& Chen, S. L. (2005). Serious games: Games that educate, train, and inform. Muska \& Lipman/Premier-Trade.

Nikolopoulou, K., \& Gialamas, V. (2016). Barriers to ICT use in high schools: Greek teachers' perceptions. Journal of Computers in Education, 3(1), 59-75. https://doi.org/10.1007/s40692-015-0052-z

Norris, C., Sullivan, T., Poirot, J., \& Soloway, E. (2003). No access, no use, no impact: Snapshot surveys of educational technology in K-12. Journal of Research on Technology in Education, 36(1), 15-27. https://doi.org/10.1080/15391523.2003.10782400

Pappano, L. (2012). The Year of the MOOC. The New York Times, 2(12), p.2012.

Scimeca, S., Dumitru, P., Durando, M., Gilleran, A., Joyce, A., \& Vuorikari, R. (2009). European Schoolnet: enabling school networking. European Journal of Education, 44(4), 475-492. https://doi.org/10.1111/j.1465-3435.2009.01407.x

Semerci, A., \& Aydin, M. K. (2018). Examining High School Teachers' Attitudes towards ICT Use in Education. International Journal of Progressive Education, 14(2), 93-105. https://doi.org/10.29329/ijpe.2018.139.7

Serin, G. (2015). The effect of gender and professional development in information and communication technology (ICT) on science teachers' use of classroom practices. Anadolu Journal of Educational Sciences International, 5(1), 20-37. https://doi.org/10.18039/ajesi.43444

Spyrou, E., Vretos, N., Pomazanskyi, A., Asteriadis, S., \& Leligou, H. C. (2018, August). Exploiting IoT technologies for personalized learning. Proceedings of the 2018 IEEE Conference on Computational Intelligence and Games (CIG) (pp. 1-8). Maastricht, the Netherlands. https://doi.org/10.1109/CIG.2018.8490454

Wastiau, P., Blamire, R., Kearney, C., Quittre, V., Van de Gaer, E., \& Monseur, C. (2013). The Use of ICT in Education: a survey of schools in Europe, European Journal of Education, 48(1), 1-27. https://doi.org/10.1111/ejed.12020

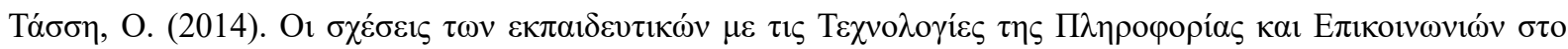

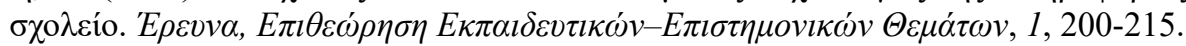

\section{Note}

Note 1. https://www.esos.gr/arthra/56452/ptyhes-tis-deyterovathmias-ekpaideysis-stin-ellada-2018

\section{Copyrights}

Copyright for this article is retained by the author(s), with first publication rights granted to the journal.

This is an open-access article distributed under the terms and conditions of the Creative Commons Attribution license (http://creativecommons.org/licenses/by/4.0/). 